\title{
The Italian Helpdesk under the Regulation (EC) No. 1272/2008 (CLP): three-year activity and experience (2009-2011)
}

\author{
Sonia D'Ilio, Maria Alessandrelli, Maria Alessandra Nania, Paolo Izzo, \\ Ludovica Malaguti Aliberti, Ida Marcello and Paola Di Prospero Fanghella \\ Centro Nazionale Sostanze Chimiche, Istituto Superiore di Sanità, Rome, Italy
}

\begin{abstract}
Introduction. The Regulation (EC) No. 1272/2008 on classification, labelling and packaging of substances and mixtures (CLP) sets further obligations for manufacturers, importers, distributors, downstream users of substances either on their own or in mixtures. According to the European mandate, each Member State has constituted its National Helpdesk to provide advice to the interested parties on their duties under this Regulation. In Italy, the contact point for questions has been established at the National Centre for Chemical Substances of the Istituto Superiore di Sanità. Functions. The responders of the Italian CLP Helpdesk process the requests that have been submitted by the dedicated website. Applicants are asked to complete the form with all the required information. The Helpdesk staff also take part in the European network of CLP, REACH and ECHA Helpdesks together with the European Commission and other parties, that is the HelpNet. Results. The present paper describes the results of the three-year activity of the Italian CLP Helpdesk (2009-2011).
\end{abstract}

Key words: Regulation (EC) No. 1272/2008, substances and mixtures, National CLP Helpdesk, classification.

Riassunto (L'Helpdesk italiano del Regolamento (CE) No. 1272/2008 (CLP): tre anni di attività ed esperienze, 2009-2011). Introduzione. Il Regolamento (CE) No. 1272/2008 (CLP) relativo alla classificazione, all'etichettatura e all'imballaggio delle sostanze e delle miscele fissa ulteriori obblighi per i fabbricanti, gli importatori e gli utilizzatori a valle di sostanze in quanto tali o in componenti di miscele. Su mandato dell'Europa, ogni Stato Membro ha stabilito l'Helpdesk Nazionale con lo scopo di fornire assistenza alle imprese nell'adempimento dei vincoli imposti da tale regolamento. In Italia, il punto di contatto per i quesiti è stato istituito presso il Centro Nazionale Sostanze Chimiche dell'Istituto Superiore di Sanità. Funzioni. Il personale dell'Helpdesk CLP italiano risponde ai quesiti posti dalle aziende inviate tramite il sito web appositamente dedicato. Su questo sito è presente una scheda da compilare, a cura delle imprese, nella quale sono richieste alcune informazioni. Inoltre, lo staff dell'Helpdesk partecipa attivamente al circuito degli Helpdesk degli Stati Membri CLP, REACH e dell'ECHA insieme alla Commissione Europea ed altre parti interessate denominato HelpNet. Risultati. La presente pubblicazione descrive i risultati dell'attività svolta dall'Helpdesk CLP italiano nel periodo di tempo che va dal 2009 al 2011.

Parole chiave: Regolamento (CE) N. 1272/2008 (CLP), sostanze e miscele, Helpdesk Nazionale CLP.

\section{INTRODUCTION}

The Regulation (EC) No. 1272/2008 on classification, labelling and packaging of substances and mixtures (CLP) [1] entered into force on 20 January 2009. It is commonly known as the Regulation CLP and will gradually replace the existing European system in 2015 with different sunset provisions. In particular, this Regulation modifies and repeals the two Directives, the dangerous substances (DSD) No. 67/548/EEC and the dangerous preparations (DPD) No. 1999/45/EC $[2,3]$. The CLP is closely linked to the Regulation No. 1907/2006 on the registration, evaluation, authorization and restriction of chemicals (REACH) $[4,5]$ and it is directly applicable to suppliers who manufacture, import, use or distribute chemical substances and mixtures. The Regulation CLP is intended to ensure a high level of protection of human health and the environment among Member States of the European Union by the harmonization of the requirements for the effective functioning of the internal market for chemical substances, mixtures and certain specific articles. The CLP maintains some of the existing labelling concepts of DSD and DPD, and incorporates the criteria of the internationally agreed Globally Harmonised System of Classification and Labelling of Chemicals (UN GHS) [6] into Community law. The GHS is the 
result of the need for a worldwide harmonized system for classification and labelling of chemicals, which is a consequence of the mandate from the 1992 Rio de Janeiro United Nations Conference on Environment and Development. This system is a model rule with no legal status, therefore, all countries have to implement it into their regulatory schemes $[7,8]$.

Article 44 of the Regulation CLP says that each Member State establishes a National Helpdesk to provide advice and assistance to manufacturers, importers, distributors, downstream users and any other interested parties on their respective responsibilities and obligations covered under the CLP. However, these Helpdesks are not intended to be focused on providing information perfectly fitted for a purpose on how the enterprises fulfill these duties. The European Chemicals Agency (ECHA) has established the ECHA Helpdesk, that provides advice and assistance to manufactures and importers registering a substance for obligations under CLP and REACH Regulations. Similarly to the National Helpdesks, it does not answer to business-specific inquiries, but it processes questions which have been submitted by the registrants through the dedicated information request web form on its website.

At EU level, the HelpNet is the network of CLP, REACH and ECHA Helpdesks with the European Commission acting as an associated member. This network is basically formed from the National Helpdesks of the Member States with observers from stakeholder Helpdesksand candidate countries. National Helpdesks are generally located in their National Competent Authorities. The main goal of the HelpNet is to support the National Helpdesks for the harmonization and the mutual comprehension in the implementation of CLP and REACH. Very challenging questions are discussed by the Members in the HelpNet exchange platform (HelpEx). The National CLP Helpdesks are asked to participate and cooperate in order to come to an agreement for the publication of the harmonized answers to the frequently asked questions (FAQ) document to be published on the ECHA web site.

The twenty-seven EU countries together with Iceland, Liechtenstein and Norway have already set their National Helpdesks. In Italy, the Ministry of Health, which was appointed as the competent authority for the implementation of both CLP and REACH Regulations [9], has charged the National Centre for Chemical Substances (CSC) of the Istituto Superiore di Sanità (ISS, Rome) to be the contact point for questions. This service was established at CSC in 2009 as the first interaction for companies who are seeking for advice in Italy, it is free of charge and basically in Italian and when required, English is the second language.

The paper describes duties and experiences of the Italian CLP Helpdesk over its three-year activity.

\section{TASKS AND FUNCTION OF THE HELPDESK}

The Italian Helpdesk started its activity in 2009, receiving the first inquire in mid-May. Applicants are allowed to submit a question and make con- tact with the Italian Helpdesk preferably by accessing to its website and completing the form with the required information. The specialized staff of the Unit of Hazard Evaluation of Chemical Substances of CSC works for the National Helpdesk on a parttime basis, together with other high level experts of the ISS who are consulted when their expertise is required. If the questions are fully in the scope of the Helpdesk CLP, they are accepted and recorded in a Question\&Answer (Q\&A) database with the replies and the personal information of the applicants. Although the responders guarantee the replies in a reasonably short period of time (generally ten days as an average time), occasionally there are technically demanding questions that might take more time to be processed. Questions are strictly handled by the staff with respect for confidentiality, all personal information collected in the Helpdesk Q\&A database will not be included or published in any document, and under no circumstances made it public.

The Helpdesk staff is not responsible for the correctness of the interpretation of the answers provided to the inquiring companies whenever a dispute arises over the compliance with Regulation CLP. The only document legally valid remains the text of the law. A disclaimer is always provided by the Helpdesk staff in each reply, an example is given: "The information provided by the CLP Helpdesk does not constitute a legal interpretation of the Regulation No. $1272 / 2008$ or endorsement by the National Centre for Chemical Substances of the Istituto Superiore di Sanità and the Ministry of Health (national competent authority for the application of Regulation CLP), but it is intended as a guidance only."

Correctness, uniformity and harmonization of the answers are the main goals of the Helpdesk personnel. The Italian staff also participates to the HelpNet Steering Group meetings, in which nominated representatives of MSs and ECHA Helpdesks cooperate in order to ensure the harmonization of answers on Regulation CLP and the high level of quality of the support at EU level. Whenever an inquire on CLP obligations raised from Europe and European Economic Area (EEA), the Italian Helpdesk will be asked to take part in the debate.

\section{RESULTS OF THE THREE-YEAR ACTIVITY}

Over the last three years, the staff has dealt with very specific and challenging topics and more general information. Helpdesk applicants are for the most part from Italian companies, however, a small number of questions has been received from foreigner enterprises or consultants. Occasionally, questions incorrectly sent to the CLP Helpdesk are redirected to the proper unit of ECHA, REACH Helpdesk or another MS Helpdesk. In fact, when a National Helpdesk is contacted by an EU company from another Member State, as a common practice, the message is forwarded to its national contact point; while, applicants from non-EU countries must be referred only to ECHA. 

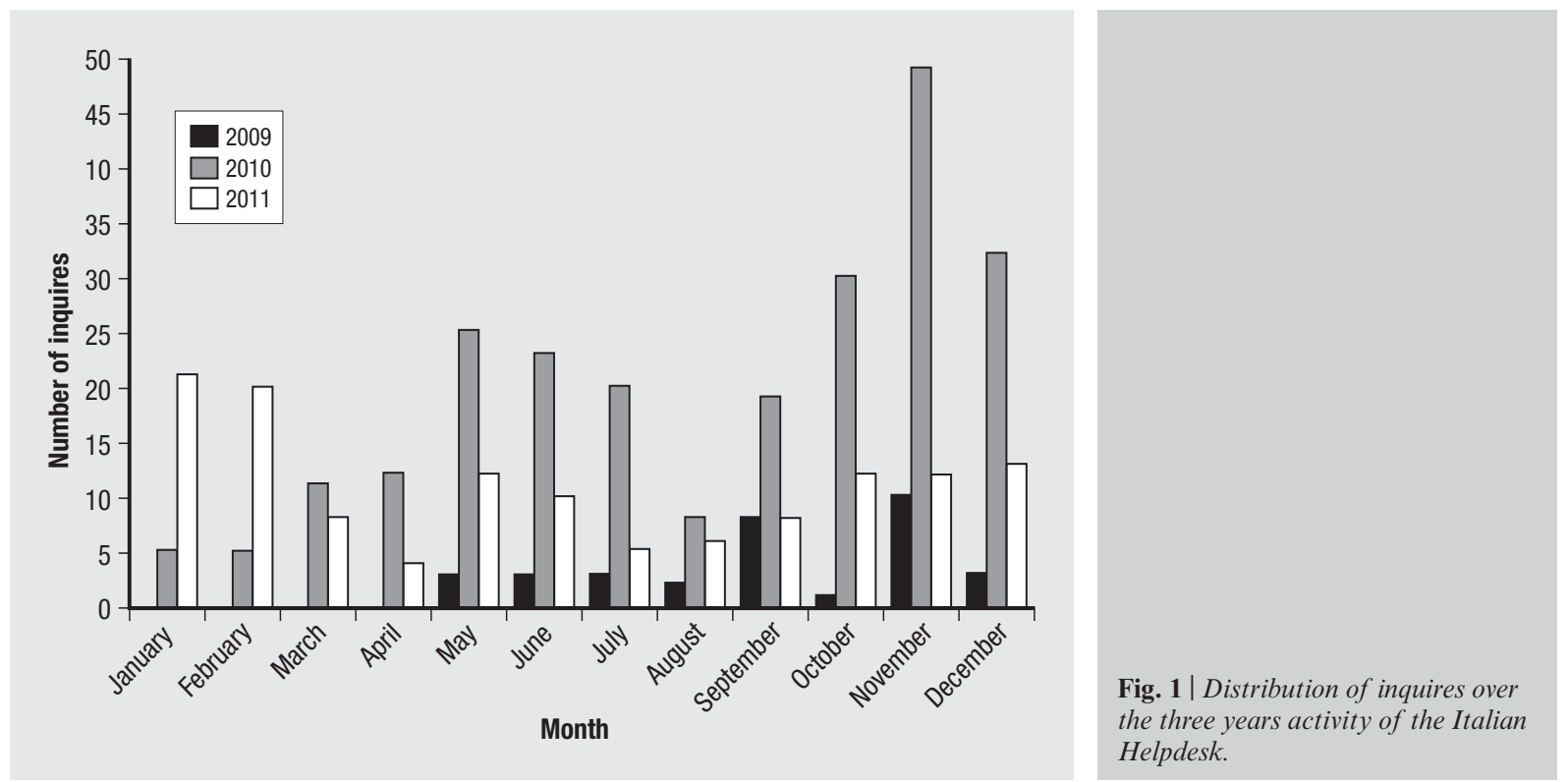

The Italian Helpdesk received a total amount of about 400 questions during its activity with a maximum peak of 239 during the year 2010. An increasing number of requests was observed according to the most important deadlines for the obligations of the two Regulations: the first date of registration of substances on 30 November 2010 (REACH), the application of the new system of classification, labelling and packaging to substances on 1 December 2010 and the notification to the Classification \& Labelling (C\&L) Inventory on 3 January 2011 (CLP). This predictable trend of the inquires is showen in Figure 1, that depicts the number of questions received by the Italian Helpdesk from the year 2009 to 2011. In August, a slight decrease can be noticed for all three years because in Italy summer holidays generally take place in this month.

Another rise in the number of questions is expected for the year 2012. This is due to the application of the $2^{\text {nd }}$ adaptation to technical and scientific progress (ATP) of CLP, that is the Commission Regulation (EU) No. 286/2011 of 10 March 2011 amending, for the purposes of its adaptation to technical and scientific progress, the Regulation CLP, and the second registration deadline of 31 May 2013 of Regulation REACH for all phase-in substances manufactured or imported in EU in quantities reaching 100 tonnes or more per year. Substances shall be classified, labelled and packaged in accordance with CLP, as amended by the $2^{\text {nd }}$ ATP, before 1 December 2012, mixtures are expected before 1 June 2015. However, substances classified, labelled and packaged in accordance with the Regulation CLP and placed on the market before 1 December 2012 are not required to be relabelled and repackaged in accordance with the Regulation No. 286/2011 until 1 December 2014; while, mixtures classified, labelled and packaged in compliance with the Directive 1999/45/EC or Regulation CLP and placed on the market before 1 June 2015, are not re- quired to be relabelled and repackaged in accordance with this Regulation until 1 June 2017.

The main business categories contacting the Italian Helpdesk are producers and consultants, followed by importers and distributors, with a small percentage of downstream users, as showed in Figure 2. In some cases, applicants did not properly fill the gaps required by the web form, thus resulting in a $1.8 \%$ group of unknown type. Notification, labelling, classification, safety data sheets, implementation and competent authority were respectively the topics of major interest for the enterprises.

The distribution of the enquires among the regions on the Italian territory was studied by exploring the Q\&A database of the Helpdesk. The outcome of this investigation was not surprising and it is displayed in Figure 3. In fact, most of the questions have been received from Lombardia followed by Veneto, Toscana and Piemonte, all of them are northern Regions with the major concentration of industrial settings. This predictable and unbalanced geographical distribution of questions may reflect disparities in the economic growth, fluctuating processes of stability be-

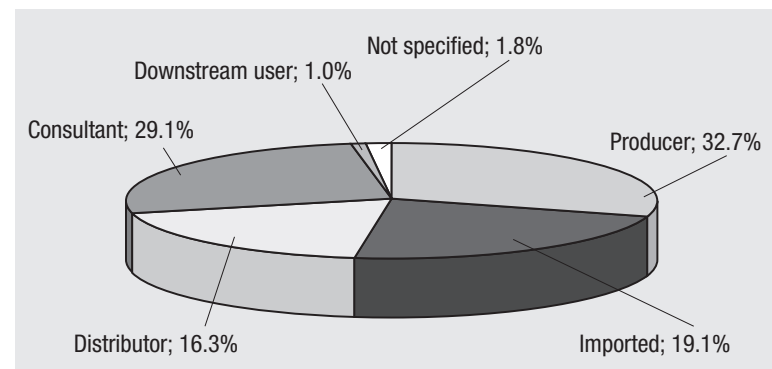

Fig. 2 | Types of applicants as defined by CLP Regulation. 

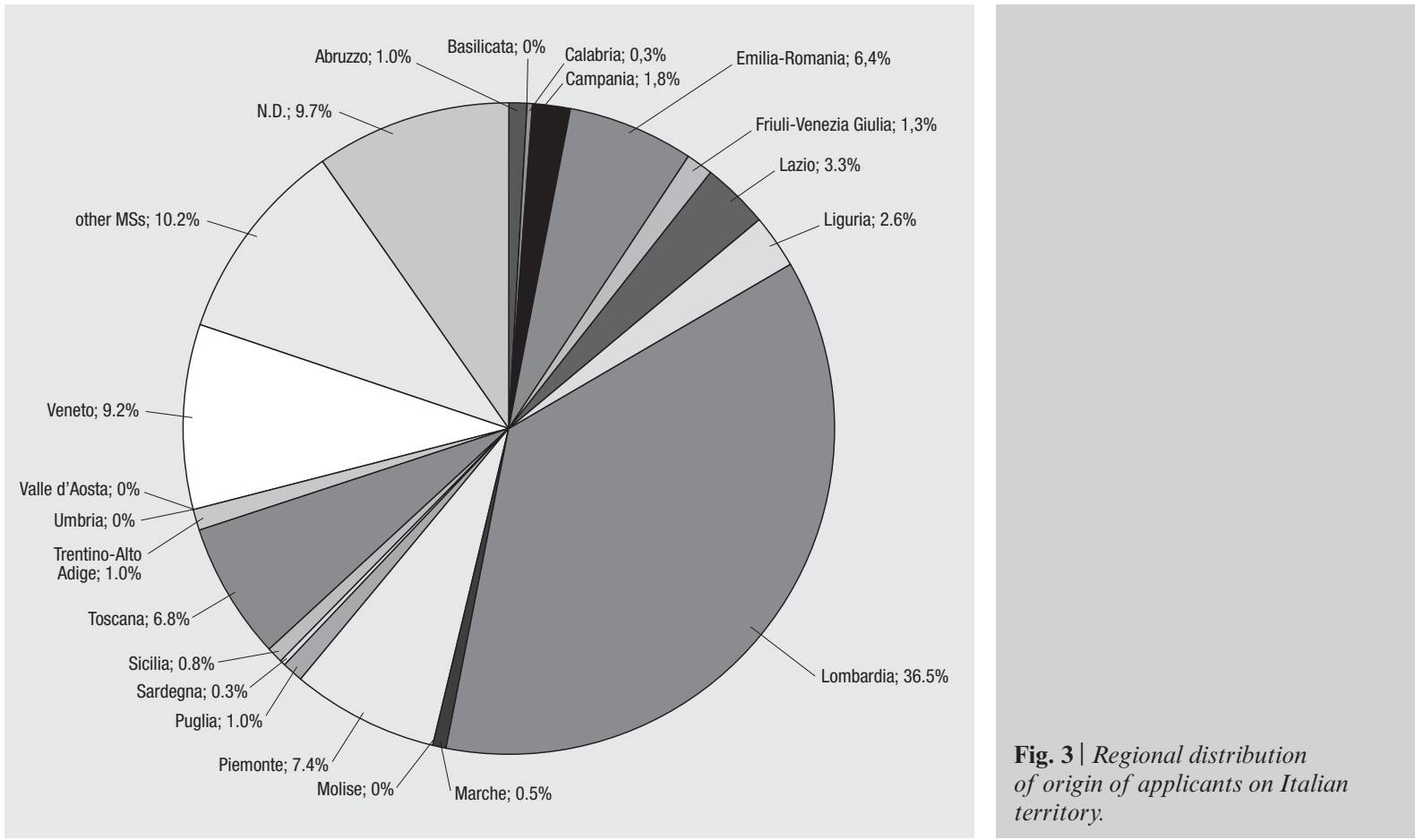

tween the North and South part of Italy and multiple determinants [10]. Four Regions, located in different parts of the country, have never sent questions to the Helpdesk staff over the three years of its activity (Basilicata, Molise, Umbria e Valle d'Aosta), finally, for a percentage of $9.7 \%$ of the questions, it was impossible to trace the Region of the senders.

\section{QUESTIONS \& ANSWERS}

A small selection of questions and answers was derived from the Q\&A database of the Italian CLP Helpdesk. They were selected by taking into account their length and appropriateness of the issue, so as to exclude too specific requests. They are listed hereafter.

1. Would substances classified as not dangerous and imported in quantities less than $1 \mathrm{t} / \mathrm{a}$ be subject to CLP notification?

No. There is no notification obligation for substances not classified as hazardous under CLP and exempted from registration under REACH.

2. Would substances exempted from registration according to Annex IV of REACH and for which an harmonized classification is not listed on Annex VI to CLP require a notification? Substances selfclassified as dangerous on the basis of criteria set in Annex I of CLP have to be notified to ECHA within one month after they have been placed on the market.

3. Is an article containing a substance of very high concern (SVHC), not intended to be released and included in the candidate list, at concentration $>$ $0.1 \%(\mathrm{p} / \mathrm{p})$ subject to obligation of labelling according to CLP?
No. Only articles classified as explosives are subject to the obligations of CLP classification and labelling.

4. Cantransitional provisions of Article61(4) of CLP be applied to substances listed in the Regulation No. 790/2009 (I ATP of the Regulation CLP) and placed on the market before 1 December 2010, classified, labelled and packaged in compliance with the Directive 67/548/CEE?

No. Regulation CLP does not allow to have a derogation for substances in stock, but only for substances placed on the market before 1 December 2010 for which no variation in their classification has been achieved (i.e., modified by the I ATP of CLP).

5. Aqueous solutions of acids and bases in different percentages can be considered as mixtures or substances according to CLP?

Substances in aqueous solutions are always considered as a mixture, except those listed with the notation " $\%$ " in Annex VI to CLP reporting a note $\mathrm{B}$ which are treated as substances and should be notified as such to the C\&L Inventory (ECHA).

6. Is the notification to the C\&L Inventory of a polymer mandatory?

If a polymer is classified as dangerous and placed on the market, the notification to the Agency is mandatory.

7. Can substances purchased from an Italian producer before 1 December 2010, stored and still in stock benefit from the derogation for classification and labelling? Yes. The transitional provisions stated in Article 61(4) for substances placed on the mar- 
ket before 1 December 2010 can be also applied to products purchased from an European supplier, unless the classification has changed in Annex VI. A full documentations on the date of placing on the market must be provided.

8. Is a company manufacturing air fresheners containing a mixture of different ingredients (i.e., perfume, essential oils and glycols) allowed to classify and label according to CLP by the 1 June 2015? Over that period of time, is it correct to use the double labelling?

Mixtures shall be classified, labelled and packaged in accordance with Directive 1999/45/CE until 1 June 2015, before that date a manufacturer and/or an importer may decide on voluntary basis to classify according to CLP. Labelling will be in compliance with CLP, as well. Both classifications will be reported on safety data sheet of the mixture until that date. Double labelling is not allowed.

9. Is a substance, classified as hazardous, manufactured and consumed in the production cycle, subject to obligation of notification? No. Only substances classified as hazardous and placed on the market are subject to obligation of notification according to Article 40 of Regulation CLP.

10. In labelling a product intended for the Italian market, English is considered to be enough?

According to article 17(2) of CLP "The label shall be written in the official language(s) of the Member State(s) where the substance or mixture is placed on

\section{References}

1. European Parliament and the Council of the European Union. Regulation (EC) No. 1272/2008 of the European Parliament and of the Council of 16 December 2008 on classification, labelling and packaging of substances and mixtures, amending and repealing Directives 67/548/EEC and 1999/45/EC, and amending Regulation (EC) No. 1907/2006. Official J European Union L 353, 31/12/2008.

2. Council of the European Communities. Council Directive of 27 June 1967 on the approximation of laws, regulations and administrative provisions relating to the classification, packaging and labelling of dangerous substances (67/548/EEC). Official J L 196, 16/08/1967.

3. European Parliament and the Council of the European Union. Directive 1999/45/EC of the European Parliament and of the Council of 31 May 1999 concerning the approximation of the laws, regulations and administrative provisions of the Member States relating to the classification, packaging and labelling of dangerous preparations. Official J L 200, 30/07/1999.

4. European Parliament and the Council of the European Union. Regulation (EC) No. 1907/2006 of the European Parliament and of the Council of 18 December 2006 concerning the Registration, Evaluation, Authorisation and Restriction of Chemicals (REACH), establishing a European Chemicals Agency, amending Directive 1999/45/EC and repealing Council Regulation (EEC) No. 793/93 and Commission Regulation (EC) No. 1488/94 as well as Council Directive 76/769/EEC and Commission Directives 91/155/ EEC, 93/67/EEC, 93/105/EC and 2000/21/EC. Official $J$ L $396,30 / 12 / 2006$.

5. Blainey M, de Avila C, van der Zandt P. Review of REACH Annex IV-Establishing the minimum risk of a substance based the market, unless the Member State(s) concerned provide(s) otherwise". In Italy, language for labelling must be in Italian, however, other languages can be added whenever there is enough space on the label.

\section{CONCLUSIONS}

The need of assuring an elevated level of protection for human health and at the same time guaranteeing the free movement of chemical substances, mixtures and certain specific articles of the internal market led to the approximation of the laws of the Member States and an harmonized classification system. The Italian CLP Helpdesk and the Network of the National Helpdesks of MSs have significantly contributed to the process of diffusion of information and assistance in the comprehension of Regulation (EC) No. 1272/2008. At EU level, several advancements have been achieved so far in the harmonization of questions and answers posed by the enterprises to the helpdesks and in the near future further efforts will be constantly required due to the issue of the third ATP of CLP [11].

\section{Conflict of interest statement}

There are no potential conflicts of interest or any financial or personal relationships with other people or organizations that could inappropriately bias conduct and findings of this study.

\section{Received on 16 April 2012.}

Accepted on 4 June 2012.

onitsintrinsic properties. RegulToxicol Pharm 2010;56:111-20. http://dx.doi.org/10.1016/j.yrtph.2009.09.016

6. United Nations. Globally Harmonized System of Classification and Labelling of Chemicals (GHS). Fourth revised edition. New York and Geneva, UN 2011. Available from: www.unece.org/trans/danger/publi/ghs/ghs_welcome_e.html.

7. Winder C, Azzi R, Wagner D. The development of the globally harmonized system (GHS) of classification and labelling of hazardous chemicals. J Hazard Mater 2005;A125:29-44. http://dx.doi.org/10.1016/j.jhazmat.2005.05.035

8. Pratt IS. Global harmonisation of classification and labelling of hazardous chemicals. Toxicol Lett 2002;128:5-15. http://dx.doi.org/10.1016/S0378-4274(01)00529-X

9. Italia. Decreto del Ministero della Salute, D.M. 22-11-2007. Piano di attività e utilizzo delle risorse finanziarie di cui all'articolo 5-bis del D.L. 15 febbraio 2007, n. 10, convertito in legge, con modificazioni, dalla L. 6 aprile 2007, n. 46, riguardante gli adempimenti previsti dal regolamento $(\mathrm{CE})$ n. 1907/2006 del Parlamento europeo e del Consiglio concernente la registrazione, la valutazione, l'autorizzazione e la restrizione delle sostanze chimiche (REACH).

10. Viesti G, Pellegrini G, Iuzzolino G. Convergence among Italian Regions, 1861-2011. Economic History Working Papers of Bank of Italy 2001;22:1-93.

11. European Parliament and the Council of the European Union. Regulation (EU) No 618/2012 of July 2012 amending, for the purposes of its adaptation to technical and scientific progress, Regulation (EC) No. 1272/2008 of the European Parliament and of the Council on classification, labelling and packaging of substances and mixtures. Official J L 179, 11/07/2012. 